\title{
Amblyomma spp. E A RELAÇÃO COM A FEBRE MACULOSA BRASILEIRA
}

\author{
Luanna Soares de Melo Evangelista ${ }^{1}$ \\ Aline Lima Oliveira ${ }^{2}$ \\ Naelson Railson de Sousa Gomes ${ }^{2}$ \\ Nathyelle Maria Sousa de Oliveira ${ }^{2}$ \\ Larissa dos Santos Sousa ${ }^{2}$ \\ Andreza Danielly Vieira Pereira ${ }^{2}$
}

\begin{abstract}
RESUMO
Carrapatos são artrópodes de grande importância para a saúde, principalmente por transmitirem doenças aos seus hospedeiros. Espécies do gênero Amblyomma possuem uma ampla variedade de hospedeiros, incluindo o parasitismo em humanos, podendo ser considerados potenciais transmissores de rickettsias do grupo das bactérias causadoras da Febre Maculosa Brasileira (FBM). O objetivo desse trabalho foi realizar uma revisão de literatura sobre as principais espécies de Amblyomma transmissoras da FMB. Foram realizadas pesquisas nas bases de dados de plataformas como SciELO, LILACS e PubMed, e os descritores utilizados foram: "Amblyomma" e "Febre Maculosa Brasileira", nos idiomas português e inglês. Foram encontrados 55 trabalhos científicos e 05 teses sobre a temática e os resultados confirmaram que os carrapatos das espécies Amblyomma sculptum, A. aureolatum e A. ovale são os principais vetores da FMB, sendo a capivara, os cavalos e os cães os mais importantes reservatórios da cadeia epidemiológica da doença. As regiões Sudeste e Sul lideram os números de casos e óbitos em humanos. É importante conhecer o ciclo de vida, o ambiente e as condições ambientais favoráveis para a manutenção dessas espécies de carrapatos, a fim de diminuir a ocorrência de zoonoses transmitidas por eles, evitando também a expansão da FMB.
\end{abstract}

Palavras-chave: carrapatos, febre maculosa, Rickettsia.

\section{Amblyomma spp. AND THE RELATIONSHIP WITH BRAZILIAN SPOTTED FEVER}

\begin{abstract}
Ticks are arthropods of great importance to health, mainly because they transmit diseases to their hosts. Species of the genus Amblyomma have a wide variety of hosts, including parasitism in humans, being considered potential transmitters of rickettsiae of the bacteria group that cause Brazilian Spotted Fever (BSF). The objective of this work was to carry out a literature review on the main species of Amblyomma that transmit BSF. Searches were carried in the databases of platforms such as SciELO, LILACS and PubMed, and the descriptors were "Amblyomma" and "Brazilian spotted fever", in the language portuguese and english. Were found 55 scientific work and 05 theses on the theme and the results confirmed that ticks of the species Amblyomma sculptum, A. aureolatum and A. ovale are the main vectors of BSF, capybara, horses and dogs being the most important reservoirs of the disease's epidemiological chain. The Southeastern and Southern regions lead the numbers of cases and deaths in humans. It is important to know the life cycle, the environment and the favorable environmental conditions for the maintenance of these tick species, in order to reduce the occurrence of zoonoses transmitted by them, also avoiding the expansion of BSF.
\end{abstract}

\footnotetext{
${ }^{1}$ Professora Adjunta II da Universidade Federal do Piauí-UFPI. Correspondência: luannaufpi@gmail.com

${ }^{2}$ Graduando em Medicina Veterinária pela Universidade Federal do Piauí - UFPI. alinelimaoliveira1612@ gmail.com
} 
Key words: ticks, spotted fever, Rickettsia.

\title{
Amblyomma spp. Y LA RELACIÓN CON LA FIEBRE MACULOSA BRASILEÑA
}

\begin{abstract}
RESUMEN
Las garrapatas son artrópodos de gran importancia para la salud, principalmente porque transmiten enfermedades a sus huéspedes. Las especies del género Amblyomma tienen una amplia variedad de huéspedes, incluido el parasitismo en humanos, y pueden considerarse transmisores potenciales de rickettsias en el grupo de bacterias que causan la fiebre maculosa brasileña (FBM). El objetivo de este trabajo fue realizar una revisión de la literatura sobre las principales especies de Amblyomma que transmiten FMB. Se realizaron búsquedas en las bases de datos de plataformas como SciELO, LILACS y PubMed, y los descriptores utilizados fueron: "Amblyomma" y "Febre Maculosa Brasileña", en portugués e inglés. Se encontraron 55 trabajo científicos y 05 tesis sobre el tema y los resultados confirmaron que las garrapatas de las especies Amblyomma sculptum, A. aureolatum y A. ovale son los principales vectores de FMB, con capibaras, caballos y perros como los reservorios más importantes la cadena epidemiológica de la enfermedad. Las regiones sureste y sur lideran el número de casos y muertes en humanos. Es importante conocer el ciclo de vida, el medio ambiente y las condiciones ambientales favorables para el mantenimiento de estas especies de garrapatas, a fin de reducir la aparición de zoonosis transmitidas por ellos, evitando también la expansión de FMB.
\end{abstract}

Palabras-clave: garrapatas, fiebre manchada, Rickettsia.

\section{INTRODUÇÃO}

Os carrapatos são artrópodes hematófagos de grande importância para a saúde pública e animal, principalmente por transmitirem doenças infecciosas e parasitárias aos seus hospedeiros, dentre eles os humanos.

O gênero Amblyomma Kock, 1844 (Acari: Ixodidae) apresenta a maior diversidade de espécies de carrapatos, com mais de 30 estabelecidas no Brasil, e uma ampla variedade de hospedeiros $(1,2)$. Esses carrapatos são considerados potenciais transmissores de patógenos e algumas espécies são relatadas parasitando humanos, sendo responsáveis por transmitir bactérias do gênero Rickettsia, especialmente Rickettsia rickettsii, principal causadora da Febre Maculosa Brasileira (FBM) $(3,4)$.

A FMB é uma doença infecciosa, aguda, febril, com difícil diagnóstico na fase inicial. Ela pode apresentar um curso clínico variável e a letalidade dos casos mais graves pode chegar a $80 \%$, se não tratada de forma precoce (5). Em animais, essa doença é pouco explorada no Brasil, dispondo na literatura, majoritariamente, de dados soroepidemiológicos, contudo já foram observadas manifestações clínicas em cães, tanto por infecção experimental (6) como natural $(7,8)$ e sintomatologia em um cavalo nos Estados Unidos (9). Cães, cavalos e, principalmente, capivaras são importantes reservatórios da cadeia epidemiológica da doença.

No Brasil, as espécies de carrapatos em destaque nessa transmissão são: Amblyomma sculptum (pertencente ao complexo Amblyomma cajannense), A. aureolatum e A. ovale $(3,10,11)$. Outras espécies de carrapatos também podem ser consideradas reservatórios de ricketsias, como A. dubitatum que parasita capivaras $(12,13)$ e até mesmo Rhipicephalus sanguineus, o carrapato do cão $(14,15)$. 
É importante destacar que a realização de pesquisas no âmbito da distribuição geográfica de espécies de carrapatos no Brasil ajuda a esclarecer sobre as condições ambientais favoráveis para a manutenção desses potenciais transmissores de patógenos. Além disso, ressalta-se que o aumento de atividades antrópicas (ecoturismo, agronegócio, pesquisas) em áreas de matas e florestas, torna-se um risco para a ocorrência de zoonoses transmitidas por esses ixodídeos (16), a exemplo da FMB.

Dessa forma, esse trabalho teve como objetivo realizar uma revisão de literatura sobre as principais espécies de Amblyomma transmissoras da Febre Maculosa Brasileira.

\section{DESENVOLVIMENTO}

Esse trabalho trata-se de uma revisão descritiva, onde a busca de dados na literatura se deu por meio de artigos científicos e teses registradas nas plataformas de pesquisas como SciELO, LILACS e PubMed, e os descritores utilizados foram: "Amblyomma" e "Febre Maculosa Brasileira", nos idiomas português e inglês. A pesquisa desses dados ocorreu no mês de maio de 2020 .

\section{Febre Maculosa Brasileira (FMB): Considerações sobre a doença}

A Febre Maculosa Brasileira (FMB) é uma doença infecciosa, aguda, de caráter febril, transmitida por carrapatos do gênero Amblyomma e causada por rickettsias, que são bactérias intracelulares obrigatórias, tendo a espécie Rickettsia rickettsii como a mais importante de ocorrência no Brasil $(3,17,18)$. Os primeiros registros de casos foram originários dos Estados Unidos, no final do século XIX e início do século XX, e se referiam à doença pela denominação "Febre Maculosa das Montanhas Rochosas" $(4,19)$.

O primeiro relato da doença no Brasil ocorreu em setembro de 1900, realizado em uma necropsia no Instituto Bacteriológico de São Paulo e após essa data, casos esporádicos foram registrados até 1929 com diagnóstico de tifo exantemático (18). A FMB reemergiu a partir da década de 80 e nos últimos anos tem aumentado, consideravelmente, o número de casos, expandindo as áreas de risco de transmissão, com aumento de registros de óbitos (4), sendo considerada um importante problema de saúde pública no país.

A FMB tem maior ocorrência nas regiões Sudeste e Sul, destacando o estado de São Paulo, com o maior número de casos e óbitos, seguido de Santa Catarina e Minas Gerais (20), com picos de incidência nos meses de agosto a outubro, coincidindo com o tempo mais quente e seco e com o ciclo das formas mais jovens dos carrapatos $(19,21)$. A doença tem se expandido para estados antes considerados indenes como os da região Norte (Tocantins, Amazonas e Rondônia), Nordeste (Bahia, Ceará e Paraíba), além de todos os estados do Centro-Oeste (20), com uma tendência de urbanização. De acordo com a Portaria do Ministério da Saúde de Consolidação n ${ }^{\circ} 4$ de 03 de outubro de 2017, todo caso de FMB é de notificação obrigatória às autoridades locais de saúde, devendo-se realizar investigação epidemiológica em até 48 horas após a notificação.

A transmissão da doença ocorre durante o hematofagismo dos carrapatos em qualquer uma de suas fases de vida (22) e as principais espécies envolvidas nesse ciclo são: Amblyomma sculptum, A. aureolatum, A. ovale $(3,10,11)$, bem como o A. dubitatum $(12,23)$. Alguns animais são considerados os principais hospedeiros desses carrapatos como capivaras, cavalos e cães, porém outros animais domésticos e silvestres também podem se infectar com as rickettsias causadoras de FMB (24).

Em humanos, a doença é multissistêmica, com período de incubação curto de 2 a 14 dias e as manifestações clínicas iniciais podem ser relacionadas a qualquer outra infecção, sendo observados quadros de febre, mialgia, artralgia, cefaleia, mal-estar, náuseas e vômitos (25), dificultando o diagnóstico no início da infecção. $O$ que pode sugerir a doença é o 
histórico do paciente com relato de ter sido picado por carrapato ou ter sido exposto às áreas infestadas por esses ixodídeos e, ainda, por apresentar exantema macular em algumas áreas do corpo que, geralmente, aparece entre o segundo e o quinto dia da infecção, também representada por uma escara de inoculação, porém essa sintomatologia pode estar ausente nos casos mais graves $(21,26)$.

Uma grande parte dos pacientes desenvolve a doença em sua forma moderada a grave, necessitando de serviços hospitalares e, normalmente, os indivíduos procuram atendimento médico por mais de duas vezes, pois os sintomas costumam ser confundidos com outras doenças, como dengue e outras viroses, favorecendo ao aumento da ocorrência de óbitos (27).

Em casos mais graves, podem ser observados quadro de sepse com comprometimento pulmonar, insuficiência respiratória aguda, insuficiência renal aguda e lesões neurológicas com meningite e encefalite (4). Quanto mais tardio é o diagnóstico, maior é a chance de mortalidade.

A melhor forma de prevenção da FMB é evitar áreas que tenham sido relatadas com a presença de carrapatos, principalmente em matas e florestas próximos a rios. É importante que numa eventual exposição a essas áreas, o indivíduo mantenha-se protegido, com o uso de roupas claras que facilitem a identificação dos carrapatos (casos eles fiquem aderidos), e essas roupas devem cobrir adequadamente os membros e o pescoço, além do uso de calçados fechados (21).

\section{Carrapatos do gênero Amblyomma e a relação com FMB Amblyomma cajennense Fabricius 1787}

Amblyomma cajennense é popularmente conhecido como "carrapato-estrela" ou "rodoleiro", suas ninfas são chamadas de "vermelhinhos" e as larvas de "micuins" $(25,28)$. A espécie foi descrita pela primeira vez por Fabricius 1787, sendo denominada de Acarus cajennensis, com base em um espécime coletado na cidade de Cayena (Guiana Francesa). Em 1844, quando Koch propôs o gênero Amblyomma, ele incluiu essa espécie com a denominação de Amblyomma cajennense (10).

Até pouco tempo atrás, A. cajennense (Fabricius, 1787) era considerado uma espécie única de carrapato no Novo Mundo. Estudos recentes dividiram esse táxon em seis espécies, sendo que A. cajennense (sensu lato) (s.l.) é atualmente representada por duas espécies no Brasil: A. cajennense (sensu stricto) (s.s.) e A. sculptum (Berlese, 1888), porém a distribuição geográfica desses carrapatos ainda é pouco conhecida (29).

Nava et al. (30) indicaram que a espécie A. cajennense (s.s) é encontrada predominantemente na região amazônica da América do Sul, e no Brasil se mantém nos estados de Roraima, Rondônia, Pará, Tocantins, Maranhão, Mato Grosso e Goiás, regiões de clima equatorial. Este carrapato tem pouca relação na transmissão de agentes patogênicos aos humanos (29), não sendo associado com a FMB.

\section{Amblyomma sculptum Berlesse 1888}

A espécie Amblyomma sculptum (Berlese, 1888) pertence ao complexo A. cajennense (Fabricius, 1787) e é considerada o vetor mais importante da bactéria Rickettsia rickettsii, agente etiológico da FMB (29), sendo o principal representante do gênero Amblyomma na região Sudeste do Brasil (30). Existem muitas variações genéticas entre as populações dessa espécie na região em questão (31), sendo importante analisar se a diversidade genética desse carrapato pode estar relacionada ao grau de susceptibilidade à infecção por rickettsias e ao número de casos da doença (10).

Essa espécie é encontrada no norte da Argentina, Bolívia e Paraguai, além de toda a região Sudeste e Centro-Oeste do Brasil, e os estados de Rondônia, Pará, Tocantins, 
Maranhão, Piauí, Pernambuco e Bahia, áreas de clima tropical, como grande parte dos biomas Mata Atlântica, Cerrado, Pantanal e Caatinga $(10,11)$.

Em zonas de transição do Cerrado e Amazônia podem ser encontradas as duas espécies A. cajennense (s.s) e A. sculptum, sendo difícil identificá-las corretamente nessas áreas, uma vez que são poucas as diferenças morfológicas entre ambas, uma delas está no formato da abertura genital das fêmeas, A. cajennense (s.s) apresenta abertura vulvar em forma de "V" e A. sculptum em forma de "U", porém as ninfas e os machos são muito semelhantes $(29,30)$, necessitando de dados morfológicos e genéticos para a correta identificação dessas espécies. A figura que mostra essa diferença entre as fêmeas está descrita em Martins et al. (29).

O A. sculptum pode ser encontrado parasitando capivaras, cavalos e cães (considerados hospedeiros primários, assumindo uma grande importância na cadeia epidemiológica da FMB), bem como bovinos, suínos, felinos, algumas aves silvestres, gambás, macacos bugios e humanos $(3,22,24,30,32)$.

A manutenção desse ixodídeo numa determinada área, possivelmente, depende da existência de pelo menos um de seus hospedeiros primários (7). Esses autores afirmaram que dois cães foram infectados por FMB em uma área endêmica da doença na cidade de São Paulo. Os animais, após voltarem de áreas de uma mesma fazenda da região, estavam infestados de carrapatos, possivelmente A. sculptum, uma vez que os tutores relataram a presença de capivaras no ambiente da fazenda. Os exames confirmaram sorologia e teste molecular de reação em cadeia pela polimerase (PCR) positivos para $R$. richettsii em ambos. Eles apresentaram febre, letargia e anorexia, um deles apresentou ainda diarreia, hematoquezia e sinais neurológicos, e o outro também teve vômito.

Em outro trabalho, foi realizada a avaliação de 115 amostras sanguíneas de cães domiciliados próximos a fragmentos de mata de uma área de preservação ambiental do estado do Rio de Janeiro e um deles foi positivo para $R$. rickettsii por PCR, esse animal apresentou alguns sinais clínicos sugestivos da FMB, como letargia, anorexia, emagrecimento e linfonodos edemaciados (8), confirmando que o cão doméstico é susceptível à infecção natural por esta rickettsia.

Uma pesquisa realizada também no estado do Rio de Janeiro, com 253 cães, constatouse que $67 \%$ dos animais avaliados foram sororreagentes para $R$. rickettsii, servindo como fonte de infecção para a FMB naquele ambiente. Muitos dos cães positivos tinham o hábito de transitar por florestas, matas, áreas ribeirinhas ou de manterem contato com outros animais, como cavalos e capivaras (33), características de muita importância para a ocorrência da doença. Os autores também afirmaram que os dados foram coletados dias após um surto de FMB em humanos ocorrer na região.

Conforme dados publicados por Sousa et al. (27), após a descrição de 15 casos confirmados de FMB na região metropolitana de Belo Horizonte-MG, em 2017, 10 deles evoluíram para óbito. Nessa região, carrapatos de algumas espécies foram colhidos, sendo que A. sculptum foi a única espécie identificada como infectada por rickettsias, no município de Contagem, segundo local com maior número de óbitos pela doença no estado de $\mathrm{MG}$, confirmando que o encontro de ixodídeos infectados pode favorecer o aumento de indivíduos contaminados e o risco de mortalidade pela FMB. Outra informação relevante desse trabalho é que de acordo com o histórico dos casos confirmados da doença, 10 indivíduos tiveram contato com carrapatos, 9 com cavalos, 5 com capivaras e todos tinham frequentado áreas de mata e rio, mais uma vez afirmando que o local estudado pode ser considerado uma área de risco para a doença.

Após a notificação de um caso fatal de FMB no município de Floresta-MG, carrapatos e soros de três cães, três cavalos e três humanos foram coletados. Os animais tinham livre acesso a matas habitadas por capivaras e todos foram reagentes a $R$. rickettsii, com títulos elevados, indicando exposição recente à rickettsia. Dentre os carrapatos encontrados, a 
espécie A. sculptum foi a de maior ocorrência. Apesar de os humanos revelarem resultados negativos, a área pode ser sustentada como endêmica, caracterizada por baixa incidência de FMB, porém com riscos de novos casos (34).

Sangioni et al. (35) realizaram um estudo sorológico em São Paulo, também com cães, cavalos e humanos em áreas endêmicas e não endêmicas para a FMB. Os humanos não apresentarem sorologia positiva ao teste empregado, contudo os autores apontaram que os cavalos se mostraram excelentes sentinelas, uma vez que os animais soropositivos foram considerados como um método útil de vigilância da FMB nas áreas onde os seres humanos estavam mais expostos ao carrapato vetor.

Existem poucos trabalhos na literatura confirmando a infecção de FMB em cavalos, possivelmente por não ser uma doença com manifestação clínica aparente nesses animais, porém um relato mostrou um cavalo adulto que apresentou febre, taquipneia e anorexia no Sudeste dos EUA (9). Ainda não foram encontrados registros de sintomatologia clínica em equinos infectados por rickettsias nos trabalhos realizados no Brasil.

Ueno (36) observou elevada resposta imunológica em cavalos experimentalmente infectados por $R$. rickettsii numa área endêmica para a FMB no estado de São Paulo, porém sem manifestações clínicas e transmitindo a bactéria para uma quantidade muito pequena de carrapatos. Cavalos e cães são animais muito próximos ao homem, facilitando, assim, a manutenção da doença nesses hospedeiros.

Trabalhos apontam que nas regiões Sul, Sudeste e Centro-Oeste do Brasil a presença da espécie A. sculptum e capivaras tornaram-se muito importantes para a ocorrência e manutenção da FMB $(5,20,37)$. Em Goiânia-GO, no ano de 2015, um professor universitário foi diagnosticado com a doença após ser picado por carrapatos dessa espécie no campus universitário da UFG, possivelmente, provenientes de capivaras, uma vez que elas habitam a região do campus, transitando às margens das represas que existem no local (20).

Em outro campus universitário, grupos de capivaras que viviam na região da UFSCARAraras, São Paulo, foram observadas e algumas capturadas para a coleta de carrapatos, sendo que a espécie amplamente encontrada tanto nos animais como no próprio ambiente também foi A. sculptum (38), representando um risco de FMB para os estudantes e servidores dessa instituição.

Em dados recentes, rickettsias foram isoladas de A. sculptum coletados na orla da Lagoa da Pampulha-MG, sugerindo que $R$. rickettsii seja a responsável pelas infecções humanas por FMB nesse ambiente (39). A região da Lagoa da Pampulha é uma área endêmica da doença dentro da cidade de Belo Horizonte, sendo marcada pela presença de capivaras, principal hospedeiro desses carrapatos e amplificadores de rickettsias naquela região (27).

\section{Amblyomma aureolatum Pallas 1772}

A espécie Amblyomma aureolatum foi descrita pela primeira vez por Pallas (1772), porém anos depois, Koch (1844), sem considerar a espécie já descrita, nomeou-a de Amblyomma striatum. A descrição dada por Pallas foi subsequentemente desconsiderada, prevalecendo a de Koch até 1961, quando Aragão e Fonseca (40) concluíram que ambas as descrições se referiam à mesma espécie.

É conhecido como o carrapato amarelo do cão $(2,18)$, tendo ocorrência restrita à América do Sul (10) e no Brasil, apesar de o principal vetor de $R$. rickettsii ser indicado como a espécie A. sculptum, no estado de São Paulo destaca-se o carrapato A. aureolatum, principalmente na área metropolitana (áreas urbanas próximas a fragmentos de Mata Atlântica) $(2,41)$. Carnívoros silvestres são os principais hospedeiros naturais da fase adulta dessa espécie de carrapato na área nativa de Mata Atlântica, já nas áreas periurbanas e urbanas, os cães desempenham melhor esse papel (18). Larvas e ninfas de A. aureolatum, normalmente, parasitam roedores e pequenas aves (42). 
Outros municípios brasileiros, como os da região sul do país, também já registraram a presença desse carrapato; este foi encontrado parasitando além de carnívoros, cavalos e capivaras $(42,43,44)$. Locais com maior altitude tem uma maior probabilidade de ocorrência de A. aureolatum (45).

Essa espécie não apresenta alta especificidade de hospedeiros e é antropofílica, portanto numa infestação em humanos, elas podem transmitir rickettsias a estes indivíduos (3); trabalhos relataram que carrapatos adultos são os mais envolvidos nessa transmissão (46). Além disso, esses autores afirmam que um carrapato infectado requer um período de alimentação sanguínea de 2 a 10 horas para a transmissão de $R$. rickettsii aos seres humanos e orientam que pessoas que frequentam áreas de matas devem inspecionar-se rigorosamente e tão logo percebam a presença desses ixodídeos, devem removê-los para evitar uma possível infecção.

Os cães atuam como hospedeiros primários de A. aureolatum e são amplificadores nas áreas de distribuição geográfica dessa espécie de carrapato com focos da FMB (3). Eles são os animais que têm atuado no deslocamento desses carrapatos infectados para o contato com a população humana dentro dos domicílios (11), portanto, a infecção humana é, provavelmente, melhor adquirida pelo contato direto com cães infestados por estes ixodídeos.

Em uma pesquisa realizada no município de Franco da Rocha-SP, foram coletados espécimes de carrapatos da região de um parque estadual do município, dentro de áreas com e sem a presença de capivaras, bem como colheu-se soro de cães que transitavam nesse ambiente, sendo que $60 \%$ destes animais foram reagentes a $R$. rickettsii e alguns destes apresentavam $A$. aureolatum (41), sugerindo uma área de risco para a FMB aos indivíduos que trabalham e/ou frequentam esse parque ou as instituições que se localizam no entorno dele.

Piranda et al. (6) dividiram os animais em dois grupos para uma pesquisa experimental de transmissão por $R$. rickettsii. Os cães do grupo 1 foram experimentalmente infectados por $R$. rickettsii (cepa Taiaçu) isolada da espécie de carrapato A. aureolatum, e cães do grupo 2 foram infestados por carrapatos infectados por essa mesma cepa. Esse trabalho mostrou que todos os animais desses grupos apresentaram febre, letargia, anorexia, lesões oculares, anemia, trombocitopenia, além da detecção de DNA da rickettsia, sugerindo que essa cepa é patogênica para cães.

É importante frisar que em condições laboratoriais, essa espécie é mais susceptível à infecção por $R$. rickettsii do que a $A$. sculptum e mais eficiente em manter a infecção e a transmissão, porém em condições naturais, em áreas endêmicas, esses carrapatos parecem apresentar taxas de infecção mais baixas, sendo importante detectar a presença de cães soropositivos à rickettsias em áreas onde a FMB pode ser transmitida por A. aureolatum (14). Porém, a taxa de letalidade humana de FMB relacionada a transmissão por essa espécie de carrapato costuma ser elevada. De 2003 a abril de 2015, foram confirmados 65 casos de FMB nos municípios de São Paulo com registros de A. aureolatum e quase $50 \%$ de casos fatais (45). Nesse mesmo trabalho, durante o mesmo período de estudo, apenas 18 casos de FMB foram confirmados nos municípios com registros de outra espécie de carrapato, A. ovale, porém com taxa de mortalidade menor (1\%).

\section{Amblyomma ovale Koch 1844}

Essa espécie foi descrita por Koch (1844) sob o nome de Amblyomma confine, no entanto Aragão e Fonseca (40) validaram essa espécie, bem como a A. aureolatum, como pertencentes ao complexo ovale, pois, as duas espécies possuem muitas semelhanças morfológicas, com diferenças pontuais.

Os carrapatos machos de A. ovale apresentam contorno mais estreito, sulco marginal completo e espinhos menos curvados na coxa IV do que os machos de A. aureolatum, que 
possuem sulco marginal incompleto alcançando o $2^{\circ}$ festão. Nas fêmeas, a diferença está basicamente no escudo mais ornamentado, castanho claro, predominando o amarelo-dourado no A. aureolatum e o castanho com faixas esverdeadas ou acobreadas no A. ovale. Ambos os sexos também possuem diferenças nos dois espinhos das coxas I, sendo que no A. ovale são contíguos e tão longos quanto o comprimento da coxa, com o externo ligeiramente curvado na extremidade e um pouco mais longo que o interno e no A. aureolatum são contíguos, longos e subiguais, com o externo terminando em ponta reta (40). Análises de DNA reafirmaram a validade das duas espécies (47). As figuras que mostram essas estruturas morfológicas das espécies A. ovale e A. aureolatum estão descritas em Gomes et al. (48) e Quadros et al. (42).

A. ovale é amplamente distribuída nas Américas e no Brasil têm ocorrência nos estados do Sudeste e Sul, além do Mato Grosso do Sul, Goiás, Amazonas, Pará, Ceará, Bahia e Rio Grande do Norte $(47,49)$. No estado de São Paulo, essa espécie é relatada em municípios com os biomas Mata Atlântica e Cerrado, locais com menor altitude (45).

Os carrapatos adultos, normalmente, parasitam carnívoros, tendo hábito mais silvestre do que urbano, no entanto também podem ser observados em cães domésticos, principalmente aqueles utilizados para a caça, pois eles adentram as matas, se infestam e levam os carrapatos para o ambiente doméstico, podendo contaminar o homem $(45,47,50)$. Cães costumam perseguir tatus nas suas tocas e estes animais também podem ser parasitados por essa espécie de carrapato (48); já as aves e os roedores silvestres são os principais hospedeiros dos estágios imaturos desses ixodídeos $(45,47)$.

A espécie A. ovale é amplamente distribuída nas áreas de preservação da Mata Atlântica no estado de São Paulo, sendo um importante vetor de Rickettsia sp. cepa Mata Atlântica (51). Esses autores afirmaram que carrapatos adultos dessa espécie foram encontrados e coletados tanto da vegetação como dos cães avaliados, e estes estavam altamente infectados por essa cepa.

Em um trabalho realizado no litoral norte de São Paulo, 40 cães foram escolhidos aleatoriamente, dentre os que viviam próximos às áreas de mata. Eles foram examinados bimestralmente, durante um ano, para a verificação da presença de carrapatos. A espécie $A$. ovale foi a de maior ocorrência, sendo que em apenas um cão foi possível observar mais de 100 espécimes desse carrapato (52). Nesse trabalho, os autores concluíram que os cães foram parasitados por esse carrapato durante o ano inteiro, sendo mais abundantes nos períodos mais quentes do ano.

Nieri-Bastos et al. (49) também coletaram carrapatos de A. ovale de cães de duas localidades, uma no Vale Paty do Parque Nacional Chapada Diamantina, na Bahia e outra no estado do Paraná. Os carrapatos foram rastreados quanto a presença de rickettsias e dois (um de cada localidade) foram isolados e identificados com a Rickettsia sp. cepa Mata Atlântica. Dos dez cães testados sorologicamente, seis apresentaram-se sororreagentes, sendo importante observar o papel de A. ovale como vetor dessa cepa em uma variedade de florestas tropicais de Mata Atlântica.

Em 2017, sete carrapatos adultos de Amblyomma ovale foram coletados por um fazendeiro de suas roupas e corpo durante um dia de trabalho em uma área rural de um município do Espírito Santo. Por meio de PCR, foi detectado DNA de Rickettsia sp. cepa Mata Atlântica em 6 dos 7 carrapatos capturados (53), sustentando que o estado do Espírito Santo também representa um risco de infecção humana para FMB por esse agente patogênico.

No Brasil, essa espécie de carrapato está associada à transmissão de FMB sob a forma mais branda, com sintomas mais leves $(45,50)$. Spolidorio et al. (26) diagnosticaram um caso clínico humano com a Rickettsia sp. cepa Mata Atlântica em 2009, o diagnóstico foi realizado por meio da coleta e análise de uma escara da pele, na região lombar de um homem idoso. Esse indivíduo relatou ter frequentado um rancho em uma área de Mata Atlântica, na região litoral sul do estado de São Paulo e um carrapato foi retirado de sua região lombar, local onde 
apresentou a escara. Dez dias após a picada, além da escara de inoculação, ele apresentou erupção cutânea, febre, mialgia e artralgia, sinais clínicos normalmente observados em indivíduos infectados por essa rickettsia.

No estado de Santa Catarina, um caso clínico também foi registrado em uma jovem do sexo feminino, estudante do curso de Ciências Biológicas, que foi picada por um carrapato no tornozelo esquerdo, durante uma expedição ornitológica em um fragmento de Mata Atlântica no município de Blumenau-SC, em 2015 (50). Sete dias após, ela apresentou uma escara de inoculação no local da picada do carrapato, com prurido intenso e o diagnóstico molecular foi realizado por meio da crosta removida da escara, confirmando DNA de Rickettsia sp. cepa Mata Atlântica. Ela também apresentou cefaleia, mialgia, artralgia, calafrios e febre, confirmando a sintomatologia de FMB provocada por essa cepa de rickettsia.

Um homem adulto foi parasitado por carrapato após visitar uma região de floresta também no estado de Santa Catarina, onde ficou em média por 4 horas nesse ambiente e 24 horas depois sentiu um prurido na região pubiana, local onde foi encontrado o ixodídeo, o mesmo foi retirado e identificado em laboratório como sendo uma fêmea da espécie A. ovale (54). O homem não apresentou sintomas de FMB.

Em 2013, um carrapato adulto fêmea da espécie A. ovale também foi encontrado em um homem numa área periurbana de um município do Rio Grande do Sul (55). Esse carrapato foi analisado e a infecção por Rickettsia sp. cepa Mata Atlântica foi confirmada. O homem também não apresentou sintomas de FMB, porém esse episódio de parasitismo ocorreu, simultaneamente, com dois casos confirmados da doença no referido estado, sugerindo a relação desse vetor no ciclo da FMB na região.

Tanto a espécie $A$. ovale como A. aureolatum são carrapatos naturalmente infectados por rickettsias patogênicas e são comumente encontrados picando seres humanos nas áreas com casos registrados de FMB, principalmente na região Sudeste e Sul do país $(45,50,55)$. Em pesquisas de dados epidemiológicos realizadas no estado do Rio de Janeiro, Serra-Freire et al. (56) verificaram a presença de seres humanos infestados por algumas espécies de carrapatos como A. ovale, A. aureolatum, A. dubitatum e Rhipicephalus sanguineus; estes últimos também podem ser considerados reservatórios de rickettsias.

\section{Amblyomma dubitatum Neumann 1899}

Essa espécie foi descrita por Neumann em 1899 através de uma fêmea ingurgitada coletada, provavelmente, no sul da Espanha e redescrita de espécimes adultos coletados no Uruguai e no Brasil (57).

Os carrapatos da espécie A. dubitatum são encontrados em diversas áreas da América do Sul e no Brasil há registros em alguns estados, como Minas Gerais $(12,58)$, São Paulo $(2,13)$, Mato Grosso do Sul (23) e Rio Grande do Sul (59), áreas concentradas nos biomas Cerrado, Mata Atlântica (2) e Pampa (59), principalmente em ambientes silvestres.

As capivaras são os principais hospedeiros de A. dubitatum, como também de $A$. sculptum, principalmente, na região Sudeste do Brasil, podendo suportar altas cargas de infestação (58). Diferentemente de A. sculptum, ainda são poucas as informações na literatura a respeito do ciclo de vida de $A$. dubitatum, tanto na natureza como em laboratório (23).

Além de compartilharem os mesmos hospedeiros, A. dubitatum e A. sculptum também possuem características morfológicas semelhantes e se distribuem geograficamente, praticamente, pelos mesmos ambientes (56), sendo que as larvas e as ninfas de A. dubitatum são maiores que as de $A$. sculptum $(41,60)$. As principais diferenças estão no escudo e ornamentação dos carrapatos adultos das duas espécies. Em A. dubitatum, os machos apresentam dorsalmente escudo completo de cor castanho claro, com macha esbranquiçada longitudinal na porção lateral e ventralmente dois espinhos fortes e iguais na coxa I (32) já os

Evangelista LSM, Oliveira AL, Gomes NRS, Oliveira NMS, Sousa LS, Pereira ADV. Amblyomma spp. e a relação com a febre maculosa brasileira. Vet. e Zootec. 2021 mar.; v28: 001-015. 
machos de A. sculptum possuem escudo bem ornamentado e ventralmente apresentam o espinho externo maior que o espinho interno na coxa I (38).

Apesar de raro de ser encontrado, um ginandromorfo de $A$. dubitatum foi registrado pela primeira vez em uma capivara no Zoológico de Guarulhos-SP (32). Essa alteração genética ocorre em diversas espécies de vertebrados e invertebrados, incluindo os carrapatos e esse espécime apresentava características morfológicas masculinas no lado esquerdo da vista dorsal e no lado direito da vista ventral; as características femininas foram observadas no lado oposto. A figura do ginandromorfo nas vistas dorsal e ventral encontra-se em Martins et al. (32).

Com relação aos ambientes de manutenção de cada espécie, uma particularidade do $A$. dubitatum é que ele, normalmente, pode ser encontrado em áreas com fontes de água ou propensas a inundações, já o A. sculptum, além de locais próximos a rios, essa espécie se adapta bem a locais mais secos (58) e ambos já foram encontrados em humanos, porém $A$. dubitatum parece ser menos agressivo. Carrapatos foram colhidos de área urbanas e de uma reserva ecológica do município de Uberlândia-MG e a maioria dos ixodídeos encontrados foram da espécie A. sculptum (77,3\%), porém mesmo em porcentagem reduzida (22,3\%) A. dubitatum foi muito mais prevalente em duas áreas próximas as margens de rios (58).

Em contrapartida, em outro trabalho realizado em um parque estadual do município de Franco da Rocha-SP, a espécie A. dubitatum foi muito mais frequente do que a A. sculptum (41), sendo que as amostras de carrapatos foram colhidas apenas de áreas próximas a coleções hídricas, o que pode justificar o encontro da maioria dos ixodídeos ser da primeira espécie.

A capacidade vetorial de $A$. dubitatum para doenças em humanos parece ser baixa, sendo comumente associado à Rickettsia bellii, uma bactéria que não pertence ao grupo das que causam FMB, com patogenicidade desconhecida $(3,13)$, porém a Rickettsia sp. cepa Pampulha já foi encontrada nessa espécie de carrapato, quando coletado nos arredores do Lago da Pampulha, em Belo Horizonte-MG (12). Nesse trabalho, essa cepa foi registrada pela primeira vez em $A$. dubitatum e ainda não se sabia a patogenicidade dela para os humanos. Posteriormente, outros trabalhos demonstraram que $R$. rickettsii cepa Pampulha pode ser uma cepa responsável por casos clínicos de FMB em humanos na região do Lago da Pampulha (39). É comum a presença de capivaras nessa região e, consequentemente, a exposição humana a carrapatos que parasitam estes animais, sendo considerada uma área endêmica para FMB no estado de Minas Gerais (27).

Rickettsia parkeri já foi identificada em A. dubitatum e descrita pela primeira vez em uma área urbana do município de Campo Grande-MS, demonstrando o encontro de rickettsias do grupo da FMB nessa região (23). As áreas desse estudo ficavam próximas a bacias hidrográficas habitadas por capivaras e carrapatos dessa espécie.

Em outro trabalho também foram revelados DNA de $R$. parkeri em quatro de quatorze carrapatos A. dubitatum coletados de carcaças de capivaras capturadas de dois municípios do Rio Grande do Sul (59). Os resultados deste trabalho reforçam que $R$. parkeri pode ser o agente associado à FMB no Pampa brasileiro. Nessa região, é comum a atividade de caça às capivaras e os indivíduos relatam que as carcaças desses animais frequentemente são encontradas parasitadas por carrapatos, o que sugere um risco de infecção aos seres humanos.

O possível envolvimento de A. dubitatum como vetor de espécies de rickettsias envolvidas na transmissão de FMB merece uma maior atenção, uma vez que a literatura sustenta haver co-infestação com A. sculptum em capivaras, além de relatar que ambas as espécies de carrapatos podem picar o homem $(23,58)$.

No Brasil, existem vários cenários para a FMB, com base nas diferentes espécies de rickettsias causadoras da doença e de espécies de carrapatos vetores: Rickettsia rickettsii está associada a A. sculptum e A. aureolatum (24); Rickettsia sp. cepa Mata Atlântica associada a $A$. ovale (51) e $R$. parkeri ao carrapato A. dubitatum $(23,59)$, sendo que a infecção por $R$. 
rickettsii provoca nos indivíduos sintomas mais graves da FMB e tanto a Rickettsia sp. cepa Mata Atlântica como a $R$. parkeri estão relacionadas com os sintomas mais leves da doença.

Em decorrência dos registros de FMB, de seus vetores no Brasil e da ascensão do número de casos para outros locais além das regiões Sudeste e Sul, se torna necessária a conscientização da população sobre as áreas de risco para a doença, bem como a orientação de como ocorre a sua transmissão.

\section{CONCLUSÃO}

É importante conhecer o ciclo de vida, o ambiente e as condições ambientais favoráveis para a manutenção das principais espécies de carrapatos envolvidas no ciclo da FMB, sendo necessário que os indivíduos evitem áreas de matas e florestas, principalmente se confirmada a presença de capivaras, uma vez que são hospedeiros naturais desses carrapatos, além de servirem como fonte de contaminação para os animais domésticos, como cães e cavalos. Dessa forma, é possível evitar a ocorrência de zoonoses transmitidas por carrapatos, especialmente a FMB, evitando também a sua expansão para áreas urbanas e periurbanas.

\section{REFERÊNCIAS}

1. Fonseca CF, Lima DCV, Souza DS, Silva SGN, Lima JRB, Oliveira JB, et al. Distribuição espacial e abundância de carrapatos (Acari: Ixodidae) em remanescente de Mata Atlântica, Nordeste do Brasil. Pesqui Vet Bras. 2017;37(10):1085-90.

2. Franco CS. A influência dos fatores ambientais na ocorrência de carrapatos (Arthropoda, Acari, Ixodidae) e Rickettsia em área de transmissão e área de predisposição para a febre maculosa brasileira [tese]. Campinas: Instituto de Biologia, Universidade Estadual de Campinas; 2018.

3. Szabó MPJ, Pinter A, Labruna MB. Ecology, biology and distribution of spotted-fever tick vectors in Brazil. Front Cell Infect Microbiol. 2013;3(27):1-9.

4. Moraes-Filho J. Febre maculosa brasileira. Rev Educ Contin Med Vet Zootec CRMV-SP. 2017;15(1):38-45.

5. Nasser JT, Lana RC, Silva CMS, Lourenço RW, Silva DCC, Donalísio MR. Urbanização da febre maculosa brasileira em município da região Sudeste: epidemiologia e distribuição espacial. Rev Bras Epidemiol. 2015;18(2):299-312.

6. Piranda EM, Faccini JLH, Pinter A, Saito TB, Pacheco RC, Hagiwara MK, et al. Experimental infection of dogs with a Brazilian strain of Rickettsia rickettsii: clinical and laboratory findings. Mem Inst Oswaldo Cruz. 2008;103(7):696-701.

7. Labruna MB, Kamakura O, Moraes-Filho J, Horta MC, Pacheco RC. Rocky montain spotted fever in dogs, Brazil. Emerg Infect Dis. 2009;15(3):458-60.

8. Campos SDE, Cunha NC, Machado CSC, Nadal NV, Seabra Junior ES, Telleria EL, et al. Spotted fever group rickettsial infection in dogs and their ticks from domestic-wildlife interface areas in southeastern Brazil. Braz J Vet Parasitol. 2020;29(1):1-12.

9. Freese S, Sheats MK. A suspected case of rocky mountain spotted fever in an adult horse in the southeastern United States. J Equine Vet Sci. 2019;78:134-7. 
10. Garcia KB. Amblyomma sculptum BERLESE 1888, Amblyomma ovale KOCH 1844 e Amblyomma aureolatum (PALLAS 1772) (Acari: Ixodidae): diversidade genética e detecção de riquétsias em diferentes biomas do Brasil [tese]. Rio de Janeiro: Instituto Oswaldo Cruz; 2017.

11. Oliveira SV. Febre Maculosa no Brasil: situação epidemiológica atual e a distribuição geográfica de carrapatos em cenários de mudanças climáticas [tese]. Brasília: Faculdade de Medicina, Universidade de Brasília; 2017.

12. Almeida AP, Cunha LM, Bello ACPP, Cunha AP, Domingues LN, Leite RC, et al. A novel Rickettsia infecting Amblyomma dubitatum ticks in Brazil. Ticks Tick Borne Dis. 2011;2(4):209-12.

13. Brites Neto J, Brasil J, Duarte KMR. Epidemiological surveillance of capybaras and ticks on warning area for Brazilian spotted fever. Vet World. 2015;8(9):1143-9.

14. Ogrzewalska M, Saraiva DG, Moraes-Filho J, Martins TF, Costa FB, Pinter A, et al. Epidemiology of Brazilian spotted fever in the Atlantic Forest, state of São Paulo, Brazil. Parasitology. 2012;139(10):1283-300.

15. Almeida RFC, Garcia MV, Cunha RC, Matias J, Silva EA, Matos MFC, et al. Ixodid fauna and zoonotic agents in ticks from dogs: first report of Rickettsia rickettsii in Rhipicephalus sanguineus in the state of Mato Grosso do Sul, mid-western Brazil. Exp Appl Acarol. 2013;60(1):63-72.

16. Pinheiro MC, Lourenço EC, Patrício PMP, Sá-Hungaro IJB, Famadas KM. Free-living ixodid ticks in an urban Atlantic Forest fragment, state of Rio de Janeiro, Brazil. Braz J Vet Parasitol. 2014;23(2):264-8.

17. Oliveira SV, Pereira SVC, Pina FV, Fonseca LX, Serra-Freire NM, Cardoso KM, et al. Vigilância de ambientes da febre maculosa: explorando as áreas silenciosas do Brasil. Rev Panamazonica Saude. 2016;7(3):65-72.

18. Pinter A, Costa CS, Holcman MM, Camara M, Leite RM. A febre maculosa brasileira na região metropolitana de São Paulo. BEPA Bol Epidemiol Paul. 2016;13(151):3-47.

19. Meira AM, Cooper M, Ferraz KMPMB, Monti JA, Caramez RB, Delitti WBC. Febre maculosa: dinâmica da doença, hospedeiros e vetores. Piracicaba: ESALQ; 2013.

20. Martins MEP. Febre maculosa: revisão-atualização, situação Brasileira e Goiana. MultiScience J. 2016;1(5):15-23.

21. Costa GA, Carvalho AL, Teixeira DC. Febre maculosa: atualização. Rev Med Minas Gerais. 2016;26(6):1-7.

22. Del Fiol FS, Junqueira FM, Rocha MCP, Toledo MI, Barberato Filho S. A febre maculosa no Brasil. Rev Panam Salud Publica. 2010;27(6):461-6.

23. Matias J, Garcia MV, Cunha RC, Aguirrea AAR, Barros JC, Csordas BG, et al. Spotted fever group Rickettsia in Amblyomma dubitatum tick from the urban area of Campo Grande, Mato Grosso do Sul, Brazil. Ticks Tick Borne Dis. 2015;6(2):107-10.

24. Labruna MB. Ecology of Rickettsia in South America. Ann N Y Acad Sci. 2009;1166:156-66.

25. Araújo RP, Navarro MMA, Cardoso TAO. Febre maculosa no Brasil: estudo da mortalidade para a vigilância epidemiológica. Cad Saude Colet. 2016;24(3):339-46. 
26. Spolidorio MG, Labruna MB, Mantovani E, Brandão PE, Richtzenhain LJ, Yoshinari NH. Novel spotted fever group Rickettiosis, Brazil. Emerg Infect Dis. 2010;16(3):521-3.

27. Sousa OMF, Tourinho BD, Leite PL, Souza PB, Dure AIL, Veloso I, et al. Febre maculosa na região metropolitana de Belo Horizonte, Minas Gerais - Brasil: descrição dos casos e dos ambientes prováveis de infecção, 2017. J Health Biol Sci. 2020;8(1):1-6.

28. Lemos ERS. Rickettsioses. In: Coura JR. Dinâmica das doenças infecciosas e parasitárias. São Paulo: Guanabara Koogan; 2013. p.1626-45.

29. Martins TF, Barbieri ARM, Costa FB, Terassini FA, Camargo LMA, Peterka CRL, et al. Geographical distribution of Amblyomma cajennense (sensu lato) ticks (Parasitiformes: Ixodidae) in Brazil, with description of the nymph of A. cajennense (sensu stricto). Parasit Vectors. 2016;9(186):1-14.

30. Nava S, Beati L, Labruna MB, Cáceres AG, Mangold AJ, Guglielmone AA. Reassessment of the taxonomic status of Amblyomma cajennense (Fabricius, 1787) with the description of three new species, Amblyomma tonelliae n. sp., Amblyomma interandinum n. sp. and Amblyomma patinoi n. sp., and reinstatement of Amblyomma mixtum Koch, 1844, and Amblyomma sculptum Berlese, 1888 (Ixodida: Ixodidae). Ticks Tick Borne Dis. 2014;5(3):252-76.

31. Bitencourth K, Voloch CM, Serra-Freire NM, Machado-Ferreira E, Amorim M, Gazêta GS. Analysis of Amblyomma sculptum haplotypes in an area endemic for Brazilian Spotted Fever. Med Vet Entomol. 2016;30(3):342-50.

32. Martins TF, Ygayara-Souza CA, Sanches TC, Melo MA, Bolochio CE, Nagahama AA, et al. Diversidade de carrapatos (Acari: Ixodidae) em animais silvestres recebidos pelo zoológico municipal de Guarulhos. ARS Vet. 2017;33(1):20-5.

33. Poubel IT, Cunha NC, Fonseca ABM, Pinter A, Fonseca AH, Cordeiro MD, et al. Seroprevalence of Rickettsia rickettsii and Rickettsia parkeri in dogs during a Brazilian spotted fever outbreak in the State of Rio de Janeiro. Arq Bras Med Vet Zootec. 2018;70(3):667-74.

34. Labruna MB, Ceza RM, Binder LC, Rodrigues DC, Paz GF, Leite RC, et al. Investigação epidemiológica em foco endêmico de febre maculosa brasileira em Minas Gerais, Brasil. Rev Saude e Meio Ambiente. 2020;10(1):140-4.

35. Sangioni LA, Horta MC, Vianna MCB, Gennari SM, Soares RM, Galvão MAM, et al. Rickettsial infection in animals and Brazilian Spotted Fever endemicity. Emerg Infect Dis. 2005;11(2):265-70.

36. Ueno TEH. Infecção experimental de equinos por Rickettsia rickettsii e avaliação da transmissão para carrapatos Amblyomma cajennense [tese]. São Paulo: Faculdade de Medicina Veterinária e Zootecnia, Universidade de São Paulo; 2014.

37. Souza CE, Pinter A, Donalisio MR. Risk factors associated with the transmission of Brazilian spotted fever in the Piracicaba river basin, State of São Paulo, Brazil. Rev Soc Bras Med Trop. 2015;48(1):11-7.

38. Rocha VJ, Sekiama ML, Gonçalves DD, Sampieri BR, Barbosa GP, Dias TC, et al. Capivaras (Hydrochoerus hydrochaeris) e a presença do carrapato (Amblyomma sculptum) no campus da UFSCAR-Araras, São Paulo. Cienc Anim Bras.2017;18:1-15.

39. Labruna MB, Krawczak FS, Gerardi M, Binder LC, Barbieri ARM, Paz GF, et al. Isolation of Rickettsia rickettsii from the tick Amblyomma sculptum from a Brazilian

Evangelista LSM, Oliveira AL, Gomes NRS, Oliveira NMS, Sousa LS, Pereira ADV. Amblyomma spp. e a relação com a febre maculosa brasileira. Vet. e Zootec. 2021 mar.; v28: 001-015. 
spotted fever-endemic area in the Pampulha Lake region, southeastern Brazil. Vet Parasitol Reg Stud Reports. 2017;8:82-5.

40. Aragão H, Fonseca F. Notas de Ixodologia. VIII. Lista e Chave para os representantes da fauna ixodológica brasileira. Mem Inst Oswaldo Cruz. 1961;59(2):115-30.

41. Paes CB. Avaliação do risco de transmissão de Rickettsia (Rickettsia rickettsii) por carrapatos do gênero Amblyomma na área do Parque Estadual do Juquery, Franco da Rocha, estado de São Paulo, Brasil [dissertação]. São Paulo: Faculdade de Saúde Pública, Universidade de São Paulo; 2019.

42. Quadros RM, Marques SMT, Veronezi WR, Carneiro Júnior JA. Amblyomma aureolatum (PALLAS, 1772) parasitando capivara (Hidrochaeris hidrochaeris) na região do planalto catarinense-relato de caso. Sci Anim Health. 2015;3(2):151-8.

43. Lavina MS, Souza AP, Bellato V, Sartor AA, Moura AB, Famadas KM. Ixodídeos coletados em equinos e caninos no Estado de Santa Catarina. Rev Bras Med Vet. 2014;36(1):79-84.

44. Pinto DM, Aguiar CLG, Martins NS, Becker M, Damboriarena PA, Tavares NC, et al. Ocorrência de Amblyomma aureolatum (PALLAS, 1772) (Acari: Ixodidae) em cachorrodo-mato (Cerdocyon thous) (LINNAEUS, 1766), na região do bioma Pampa. Sci Anim Health. 2018;6(1):20-8.

45. Barbieri JM, Rocha CMBM, Bruhn BRP, Cardoso DL, Pinter A, Labruna MB. Altitudinal assessment of Amblyomma aureolatum and Amblyomma ovale (Acari: Ixodidae), vectors of spotted fever group rickettsiosis in the state of São Paulo, Brazil. J Med Entomol. 2015;52(5):1170-4.

46. Saraiva DG, Soares HS, Soares JF, Labruna MB. Feeding period required by Amblyomma aureolatum ticks for transmission of Rickettsia rickettsia to vertebrate hosts. Emerg Infect Dis. 2014;20(9):1504-10.

47. Guglielmone AA, Estrada-Peña A, Mangold AJ, Barros-Battesti DM, Labruna MB, Martins JR, et al. Amblyomma aureolatum (Pallas, 1772) and Amblyomma ovale Kock, 1844 (Acari: Ixodidae): hosts, distribution and 16S rDNA sequences. Vet Parasitol. 2003;113(3-4):273-88.

48. Gomes SN, Pesenti TC, Muller G. Parasitismo por Amblyomma ovale e Amblyomma fuscum (Acari: Ixodidae) em Dasypus novemcinctus (Xenarthra: Dasypodidae) no Brasil. Arq Inst Biol. 2015;82:1-4.

49. Nieri-Bastos FA, Horta MC, Barros-Battesti DM, Moraes-Filho J, Ramirez DG, Martins $\mathrm{TF}$, et al. Isolation of the pathogen Rickettsia sp. strain Atlantic rainforest from its presumed tick vector, Amblyomma ovale (Acari: Ixodidae), from two areas of Brazil. J Med Entomol. 2016;53(4):977-81.

50. Krawczak FS, Muñoz-Leal S, Guztzazky AC, Oliveira SV, Santos FCP, Angerami RN, et al. Case report: Rickettsia sp. strain Atlantic rainforest infection in a patient from a spotted fever-endemic area in southern Brazil. Am J Trop Med Hyg. 2016;95(3):551-3.

51. Sabatini GS, Pinter A, Nieri-Bastos FA, Marcili A, Labruna MB. Survey of ticks (Acari: Ixodidae) and their Rickettsia in an Atlantic rain forest reserve in the state of São Paulo, Brazil. J Med Entomol. 2010;47(5):913-6.

52. Ogrzewalska M, Lisboa LES, Branquinho-Beaudoin MS, Labruna MB, Pinter A. Sazonalidade de carrapatos Amblyomma ovale Koch em cães em uma região do litoral

Evangelista LSM, Oliveira AL, Gomes NRS, Oliveira NMS, Sousa LS, Pereira ADV. Amblyomma spp. e a relação com a febre maculosa brasileira. Vet. e Zootec. 2021 mar.; v28: 001-015. 
norte do estado de São Paulo. In: 4o Simpósio Brasileiro de Acarologia; 2013; Bento Gonçalves. Bento Gonçalves: SIBAC; 2013.

53. Acosta ICL, Luz HR, Faccini-Martínez AA, Muñoz-Leal S, Cerutti Junior C, Labruna MB. First molecular detection of Rickettsia sp. strain Atlantic rainforest in Amblyomma ovale ticks from Espírito Santo state, Brazil. Braz J Vet Parasitol. 2018;27(3):420-2.

54. Jaguezeski AM, Lavina MS, Orsolin V, Silva AS. Amblyomma ovale parasitizing a human. Comp Clin Pathol. 2018;27:535-7.

55. Voizzoni VF, Silva AB, Cardoso KM, Santos FB, Stenzel B, Amorim M, et al. Genetic identification of Rickettsia sp. strain Atlantic rainforest in an endemic area of a mild spotted fever in Rio Grande do Sul state, Southern Brazil. Acta Trop. 2016;162:142-5.

56. Serra-Freire NM, Sena LMM, Borsoi ABP. Parasitismo humano por carrapatos na Mata Atlântica, Rio de Janeiro, Brasil. EntomoBrasilis. 2011;4(2):67-72.

57. Estrada-Peña A, Venzal JM, Guglielmone AA. Amblyomma dubitatum Neumann: Description of nymph and redescription of adults, together with the description of the immature stages of A. triste Koch. Acarologia. 2002;42(4):323-33.

58. Queirogas VL, Del Claro K, Nascimento ART, Szabó MPJ. Capybaras and ticks in the urban areas of Uberlândia, Minas Gerais, Brazil: Ecological aspects for the epidemiology of tick-borne diseases. Exp Appl Acarol. 2012;57(1):75-82.

59. Weck B, Dall'Agnol B, Souza U, Webster A, Stenzel B, Klafke G, et al. Rickettsia parkeri in Amblyomma dubitatum ticks in a spotted fever focus from the Brazilian Pampa. Acta Trop. 2017;171:182-5.

60. Brites Neto J, Brasil J, Takeda GACG, Guillen AC, Labruna MB, Pinter A. Diferenciação morfométrica entre larvas de Amblyomma sculptum Berlese, $1888 \mathrm{e}$ Amblyomma dubitatum Neumann, 1899. Arq Bras Med Vet Zootec. 2018;70(5):1521-8.

Recebido em: 21/06/2020 Aceito em: 28/02/2021 